\title{
EDITORIAL \\ Emotions and coping with conflict: An introduction
}

\section{Peter J Jordan}

School of Management, Griffith University, Nathan QLD, Australia

\section{Ashlea C TROTH}

School of Management, Griffith University, Nathan QLD, Australia

W elcome to a special issue of the Journal of Management \& Organization on emotions and coping with conflict. An understanding of behaviour in the work environment is not complete until we understand the nature and effect of human emotion. We all experience emotions that affect the way we feel and behave at work. This is particularly so in conflict situations where the level of interaction between individuals results in exposure to emotions on a regular basis (Jordan \& Troth 2004). This special edition is aimed at improving our understanding of the links between emotions and conflict and the behaviours individuals engage in to cope with stressful situations that result from workplace conflict.

It is now just over 10 years since Ashforth and Humphrey (1995) urged researchers to take more notice of the impact of emotions in the workplace. Since that time, there has been increasing focus on emotions and the effect they have on organisational behaviour. Indeed, journals have published a number of special editions with a central focus on emotions including, emotions and work (Fisher \& Ashkanasy 2000), emotions and leadership (Humphrey 2002), and emotions and decision-making (Schwarz 2000). There have also been a number of books that have focused on the role of emotions at work (Fineman 2000, 2003; Lord, Klimoski \& Kanfer 2002). The field has become so prominent that a new annual series has emerged looking at issues around emotions in the workplace (Ashkanasy, Zerbe \& Härtel 2005). This special edition of the Journal of Management and Organization seeks to build on the aforementioned body of research by examining the link between emotions and two interrelated emotionally-laden experiences in the workplace conflict and coping.

Five articles are presented that address a wide range of key issues concerning emotions and coping with conflict. The topics covered in this collection include coping with work-family conflict, the emotional impact of organisational change, the impact of emotional labour on organisational outcomes, the effects of negative mood on team performance, and the impact of social support on coping with conflict. Each of the articles that have been selected for this issue identifies emotions as an important element in the workplace. Whether focussing on the difference between felt emotions and displayed emotions, identifying discrete emotions that emerge in workplaces, or the ephemeral effects of negative mood, each of the authors see emotion at the core of employee's reactions to workplace situations. A second common underlying theme of all the articles is that coping occurs within a difficult or challenging context, whether the situ- 
ation involves working in a new team, managing work-family conflict, dealing with organisational change or coping in workplaces that require emotional labour.

The selected articles also use a range of different approaches to explore these issues such as the development of a theoretical model and empirical studies using both qualitative and quantitative methods. A particular strength of many of the articles are the populations they have drawn upon for their empirical research. Three of the papers employ work-based samples. These include a manufacturing industry sample and service and public sector samples. Clearly, emotions impact on a broad range of industries. In combination, these articles provide us with a broad perspective on emotions and coping with conflict in the workplace.

The first article by Pieter Van Dijk and Andrea Kirk Brown addresses conflicting findings in the area of emotional labour and job outcomes. In particular, they look at the conceptualisation of emotional dissonance as both an antecedent and a consequence of emotional labour and argue that emotional dissonance should be viewed as a mediator in the relationship between emotional labour and outcomes. One reviewer noted that Van Dijk and Kirk Brown's research 'extends research into emotional labour to examine the mediation effects of emotional dissonance on emotional labour and emotional exhaustion'. A particular strength of this research is that it is based on a work sample across two organisations, thereby increasing the generalisability of their findings.

Melanie Bryant and Julie Wolfram Cox continue the emotional labour theme in the second article by outlining the emotional impact of an organisational change on a sample of employees. Change in organisations has always been an area where issues of emotions and conflict have been heightened. The Bryant and Wolfram Cox article focuses on the negative emotions that emerge during organisational change and highlights the need for employees to manage their emotions during this process. As one of the reviewers noted, 'The authors have highlighted an important and innovative link between organisational change and emotional labour.' Using a qualitative approach, Bryant and Wolfram Cox provide us with an insight into some of the negative emotional consequences of organisational change.

The third paper by Peter Jordan, Sandra Lawrence and Ashlea Troth presents an empirical study that investigates the links between the negative mood of team members, conflict and team performance. One of the strengths of this paper is the longitudinal approach to team interactions and the collection of an independent measure of performance. As one of the reviewers noted, 'I found this to be an interesting study that has the potential to contribute to our understanding of the role of negative affectivity (or mood) in a team context'. An interesting aspect of the Jordan, Lawrence and Troth article are the differential findings in relation to the effect of negative mood on different types of conflict and consequently team performance. They argue that focussing on individual team members' mood may provide an explanation that for resolves previous contradictory findings regarding the impact of conflict on team performance.

Jarrod Haar, in the fourth article explores the relationship between work-family conflict and family-work conflict and employee burnout. Drawing on a work-based sample, Haar examines the interaction between both work-family conflict and family-work conflict as significant predictors of employee burnout. This study is particularly unique in that it distinguishes patterns of coping that arise in response to work-family conflict from coping patterns that arise in response to family-work conflict. One reviewer noted 'This paper addresses an important and interesting topic and I particularly like the way that you address work-family conflict and as well as family-work'. Haar concludes that coping strategies used to deal with work-family conflict and family-work conflict should not be viewed universally as a panacea for the conflict-burnout relationship. 
In the final article, Sandra Lawrence develops an integrative model of coping with work-family conflict by mobilising support. As one reviewer noted this article 'make/s an important theoretical contribution by integrating the mediation and stress buffering models on workplace adjustment and a) applying this model to workfamily conflict and b) considering the supportive function and source of support.' The model outlined by Lawrence enables a more comprehensive examination of the conditions under which stress-buffering is effective in countering the demands of work-family conflict.

In total, the articles in this special edition contribute to our understanding of the inherent emotionality involved in organisational behaviour. We would like to thank those authors whose papers we were unable to accept for their submissions. We would also like to thank the reviewers for this special edition. Their expertise in research concerning emotions, coping and conflict contributed to improving each of the papers in this special edition.

\section{Acknowledgment}

This paper was funded by an Australian Research Council Discovery Grant.

\section{References}

Ashforth BE and Humphrey RH (1995) Emotion in the workplace: A reappraisal, Human Relations 48: 97-125.

Ashkanasy NM, Zerbe WJ and Härtel CEJ (Eds) (2005) Research on emotion in organizations, Volume 1: Affect and its effects in organizational settings. Elsevier Science, Oxford UK.

Fineman S (2000) Emotion in organizations. Sage, London.

Fineman S (2003) Understanding emotion at work. Sage, London.

Fisher CD and Ashkanasy NM (2000) The emerging role of emotions in work life: an introduction, Journal of Organizational Behavior 21: $123-129$.

Humphrey RH (2002) The many faces of emotional leadership. The Leadership Quarterly 13: 493-504.

Jordan PJ and Troth AC (2004) Managing emotions during team problem solving: Emotional intelligence and conflict resolution. Human Performance 17(2): 195-218.

Lord RG, Klimoski RJ and Kanfer R (2002) Emotions in the workplace: Understanding the structure and role of emotions in organizational behavior (J-B SIOP Frontiers Series). Jossey Bass, San Francisco CA.

Schwarz N (2000) Emotion, cognition, and decision making. Cognition and Emotion 14: 433-440.

\section{CALLS FOR PAPERS}

\section{Journal of Management \& Organization (ISSN 1833 3672) special issues}

\section{GLOBAL SERVICE SECTOR MANAGEMENT, edited by Nils Timmo and Peter Haynes} Manuscript submission deadline - 31 October 2006

AUSTRALASIAN ENTREPRENEURSHIP, edited by Trish Corner and Kathryn Pavlovich Manuscript submission deadline - 30 November 2006

Author Guidelines are available at www.jmanorg.com. Please indicate the title of the special issue and submit to the Editor at JMOEditorial@e-contentmanagement.com 